\title{
LIBERTAD Y PROYECTO DE VIDA DE LOS ADOLESCENTES VÍCTIMAS DE ABUSO SEXUAL
}

\section{FREEDOM AND LIFE PROJECT OF ADOLESCENTS VICTIMS OF SEXUAL ABUSE}

\author{
Jeannette Oyarce Delgado ${ }^{1}$ \\ Docente \\ Universidad de San Martín de Porres \\ Jane1005@hotmail.com
}

Perú

\section{SUMARIO}

- Introducción

- Libertad

- Elección

- Autodeterminación - Autonomía de la voluntad

- Proyecto de vida

- Libertad sexual

- Jurisprudencia de la Corte Suprema de Justicia

- Protección jurídica al menor, víctima de abuso sexual por pre-valimiento

- Casos en que se ha vulnerado la libertad

- Conclusiones

\section{RESUMEN}

$\mathrm{Si}$ bien es cierto, las personas mayores de 14 años pueden decidir libremente sobre su sexualidad y no se requiere que alcancen la mayoría de edad para hacerlo, también es verdad que los adolescentes se encuentran en plena estructura de su personalidad y al presentarse determinadas circunstancias pueden ser manipulados, como es el caso del requerimiento para prácticas sexuales efectuado por el padre, padrastro, tutor, profesor, psicólogo u otra persona que ejerza autoridad sobre estos, en cuyo supuesto, su autodeterminación sexual o consentimiento es afectado por éste grado de dependencia.
El derecho penal no brinda protección a los menores a partir de los 14 años, que son víctimas de abuso por parte de los adultos que ejercen autoridad o control sobre ellos, por su parte, la Corte Suprema de Justicia, jurisprudencialmente, ha señalado que las decisiones que adoptan los adolescentes en las circunstancias descritas, constituyen el libre ejercicio de su sexualidad.

La presente investigación analiza el grado de libertad, autonomía de la voluntad y derecho al bienestar de los adolescentes, los mismos que dependen de otros individuos para obtener la satisfacción de sus necesidades básicas como alimentación, vivienda y educación y no poseen la capacidad para autodeterminarse libremente, hemos considerado necesario utilizar el método inductivo, analizado estos casos, evidenciándose la manipulación de la que fueron objeto los menores, concluyendo que estos adolescentes no gozaron de libertad cuando aceptaron este acceso carnal y que producto de estas vivencias, han sufrido secuelas emocionales crónicas, por lo que consideramos debe sancionarse estas conductas.

\section{ABSTRACT}

Although it is true that people over 14 can freely decide about their sexuality and they are not required to reach the age of majority to do it, it's also true the teenagers are in the middle of their personality structure and when certain circumstances are presented

1 Magister en Derecho Penal por la Universidad de San Martín de Porres. 
they can be manipulated as is the case of the requirement for sexual practices carried out by their father, stepfather, tutor, teacher, employee, psychologist, or another person who exercises authority over these, in which case, their sexual self-determination or consent is affected by this degree of dependency.

The criminal law does not provide protection to children under 14, that are victims of abuse by adults who exercises authority or control over them, by their part, the Supreme Court of Justice, jurisprudentially, has been signaled that the decisions adopted by adolescents in the circumstances described, constitute the free exercise of their sexuality.

The next investigation analyze de degree of freedom, autonomy of will and the right wellness of teenagers, the same ones that depend on other individuals to obtain the satisfaction of their basic needs like food, housing and education and do not possess the ability to freely self-determine, we have considered necessary to use the inductive method, analyzing these cases, having evidence of the manipulation of which the children were subjected, concluding that these adolescents did not enjoy freedom when they accepted this carnal access and what product of these experiences, have suffered chronic emotional emotions, for which these behaviors must be sanctioned.

\section{PALABRAS CLAVE}

Autodeterminación, elección, derecho al libre desarrollo, violación sexual

\section{KEYWORDS}

Self-determination, choice, right of development, life project.

\section{INTRODUCCIÓN}

¿La circunstancia que una persona pueda elegir entre dos alternativas basta para afirmar que goza de libertad? Consideramos que ello no es así, puesto que para contestar dicha interrogante se debe tener en consideración el contexto en que se verifica esa elección, esto es, si realmente el sujeto está ejerciendo libremente este derecho o está actuando condicionado por las circunstancias.
En el presente estudio analizamos el caso del adolescente entre 14 y18 años, cuya etapa de vida se encuentra en pleno desarrollo físico y psicológico, sus necesidades básicas son proporcionadas por otras personas y no goza de autonomía para elegir dónde o con quien vivir o estudiar; en el supuesto que este menor de edad sea requerido para sostener prácticas sexuales, por su padre, madre, tutor, padrastro, madrastra, profesor, sacerdote, psicólogo u otra persona que ejerza autoridad sobre éste, tendrá un margen de elección muy limitado, ya que esta situación de superioridad influirá coartando su libertad, convirtiéndose en una víctima que emite un consentimiento viciado.

El hombre es un ser digno, por consiguiente no puede ser utilizado como un instrumento, como medio para obtener otros fines, el ser humano tiene valor per se y no puede ser abusado, cosificado o eliminado por el interés o el beneficio de otros seres humanos, nuestra Constitución Política del Estado declara que la persona humana es el fin supremo de la sociedad y del Estado; por consiguiente, todo nuestro ordenamiento debe estar al servicio del hombre, con la finalidad que éste pueda desarrollarse a plenitud, garantizándosele la vigencia de sus derechos fundamentales; los menores que se encuentran en la situación descrita y son víctimas de abuso por parte de las personas que, por el contrario, debieran prodigarles, seguridad y asistencia, merecen una protección jurídica por parte del Estado, ya que dichas vivencias dejan huellas o secuelas psicológicas al saberse utilizados como instrumentos para la satisfacción sexual de quienes ejercían autoridad sobre ellos, por consiguiente, en las siguientes líneas analizaremos la libertad, sus concepciones, autodeterminación, proyecto de vida, libertad sexual y veremos casos en los cuales menores fueron víctimas de este abuso.

El presente artículo resulta de suma trascendencia ya que en la doctrina y jurisprudencia nacional no se ha realizado un análisis respecto a la autodeterminación de estos menores entre 14 y 18 años, cuya libertad estaría siendo limitada, por lo que permitirá abordar a profundidad este tema que se encuentra íntimamente relacionado con un sector de la población especialmente vulnerable, abriéndose el debate sobre la necesidad de sancionar penalmente estas conductas. 


\section{LIBERTAD}

La libertad se considera un derecho, un atributo del hombre, anterior y superior a la sociedad misma, que constituye la esencia de las relaciones sociales y la base de la sociedad. Ha sido y continúa siendo objeto de profundas discusiones filosóficas, se precisa que hay dos concepciones de libertad que poseen supuestos y conclusiones contradictorias. En la primera, la libertad es algo maravilloso, eleva al hombre, le da una condición única e inconmensurable, es la esencia de la humanidad, su logro es más importante que todas las demás conquistas, somos libres y esta es la razón que seamos mejores. La segunda postura, cuestiona la libertad ya que ésta es una carga, el hombre sufre por ella y no es capaz de tolerarla, la libertad le exige al hombre cosas que no puede realizar, no posee la fuerza ni la dimensión para soportar la libertad, lo que la humanidad realmente desea, aquello a lo que aspira es la autoridad, encontrar a quien rendirle culto Bergmann, F. (1981).

El concepto de libertad ha sido utilizado en diversos sentidos y acepciones, Isaiah Berlin, uno de los principales pensadores liberales del siglo XX, desarrolló dos sentidos de libertad: El sentido positivo, que se deriva del deseo por parte del individuo de ser su propio dueño, su vida y decisiones deben depender del mismo, y no de fuerzas exteriores, sean éstas del tipo que sean, que el hombre sea el instrumento de sí mismo y no de los actos de voluntad de otros, ser sujeto no objeto, ser consciente de sí mismo, que tiene responsabilidad de sus propias decisiones y es capaz de explicarlas en función de sus propias ideas y propósitos. El sentido negativo de la libertad es que el hombre pueda actuar sin ser obstaculizado por otros, con ausencia de barreras o interferencias. No es libre en la medida en que otros le impiden hacer lo que podría hacer si no se lo impidieran Berlin, I. (1958).

Así, respecto al sentido positivo de la libertad, Fernández S. (2015) acota que es la capacidad inherente al ser humano de valorar, elegir $\mathrm{y}$ preferir por sí mismo, entre uno y otro acto o conducta sin límite alguno, señala las dos instancias de la libertad, la ontológica, la atribución del ser mismo del hombre, lo que caracteriza al ser humano, lo diferencia de los demás entes, el único ser espiritual capaz de vivenciar valores; y, la libertad fenomenológica, es el proyecto originario que surge de una decisión libre, en trance de ejecución, de su realización en el mundo exterior, esto es, la decisión-elección libre del ser humano, su proyección en el mundo exterior, mediante su fundamental proyecto de vida y todos aquellos proyectos que, sin interrupción, se suceden en la cotidianidad del existir. Por ello señala que la libertad es sinónimo de proyecto, el ser humano, en cuanto libre, vive permanentemente proyectando.

Por otro lado, con relación a las manifestaciones de la libertad, Castillo, G. (2007) ${ }^{2}$ afirma que el ser humano posee una libertad esencial, no se debe confundir con la libertad pragmática, con la posibilidad que tenemos de hacer una cosa u otra, menos debemos de confundir el sentimiento de ser libres con la verdadera libertad. Es la libertad de opción que lleva a elegir entre una cosa $u$ otra, sin embargo, normalmente nuestra libertad de opción está limitada por las mismas cosas sobre las que se opta. Sería difícil decir que una persona es libre porque puede salir por la ventana de su décimo piso, ya que ello es destructivo, sería una falsa libertad. Es la libertad esencial, la que nos hace capaces de hacer el bien, se trata de un nivel mayor que el de la mera libertad opción que está en el nivel de la simple naturaleza. La libertad esencial conlleva el ejercicio de virtudes morales que llevan a saber elegir las mejores alternativas, a saber, tomar las mejores decisiones ya que se elige teniendo en cuenta la verdad y el bien verdadero.

En el mismo sentido, Farrel, M. (1989) señala que el ser humano haciendo uso de su libertad en ocasiones realiza actos que originan un perjuicio a su proyecto de vida, como por ejemplo consumir drogas o mantener relaciones sexuales indiscriminadamente y sin protección, ya que puede originar estados de dependencia a las sustancias alucinógenas, contraer enfermedades de transmisión sexual como el sida, o embarazos no deseados. Farrel distingue entre la autonomía del momento, y la autonomía disposicional, que abarca la vida

2 Ella ejemplifica que los sentimientos pueden engañar, una adolescente puede sentirse gorda cuando en realidad está delgada. A veces pueden sentir que estudiar es un mal que hay que evitar cuando en realidad es un bien. Puede elegir estudiar o ver televisión, pero si se trata de elegir lo que a uno de saber elegir. Precisa que el ser humano tiene limitaciones y para empezar a ser libres realmente hay que superar dichas estas, de lo contrario seremos esclavos de nuestra ignorancia, de nuestra mentira y de nuestro egoísmo. 
autónoma de la persona considerada como un todo. Si las acciones del presente comprometen seriamente su autonomía disposicional, habría entonces un motivo para interferir con el individuo y contrariar su yo actual.

Coincidiendo con lo expuesto, se señala que la libertad y autonomía de las personas deben de reconocerse no como realidades desteleologizadas que actúan de modo desbocado, sino que deben concebirse como realidades esencialmente limitadas y dirigidas a la consecución de un fin: el perfeccionamiento de todos los hombres en cuanto hombres. La manera que tiene el hombre de alcanzar su perfeccionamiento es a través de la realización de actos, el hombre actúa y a medida que actúa pone en acto una serie de potencialidades. El acto o el ejercicio realizado, debe ser libremente requerido $\mathrm{y}$, por ello, libremente decidido. Castillo, L. (2005)

Al respecto Savater, F. (2003) precisa que el arte de vivir consiste en discernir entre las diferentes formas de actuar y valorarlas. De acuerdo con la finalidad que se pretende, las cosas se pueden hacer bien, regular o mal o incluso dejar de hacerse. Si elegir lo bueno es afirmar y reforzar lo que somos, exaltar nuestra condición en su complejidad, la opción por lo malo supondrá desmentirnos, disminuirnos y mutilarnos voluntariamente, rebelarnos contra lo que somos y quienes somos.

Consideramos que en determinadas ocasiones resulta necesario restringir la libertad del momento, en atención a la protección de denominada libertad disposicional, o a las consecuencias derivadas de determinadas decisiones, sobre todo cuando se trata de menores de edad en las circunstancias que ocupan el presente artículo.

En sentido contrario se pone énfasis al señalar que el individuo es el único juez de su plan de vida, de sus deseos y sus ambiciones. El yo que cuenta es el yo actual, no es un supuesto yo "superior". Si el individuo está satisfecho con el alcohol no puede forzárselo a adoptar otro plan de vida con el argumento de que éste contribuye a que él se realice.

Respecto a la relación existente entre la libertad económica y la libertad civil, (aspecto que en cierta forma guarda relación en nuestra investigación, en los supuestos en los cuales la víctima depende económicamente del abusador), resulta pertinente citar a Constanza M. (2007) quien precisa que la libertad económica esnecesariaparaalcanzary conservar la libertad civil, la amenaza fundamental a la libertad es el poder de coaccionar, ya esté en manos de un monarca, de un dictador o de una momentánea mayoría. La libertad económica dispersa el poder, la preservación de la libertad requiere la eliminación de la concentración de poder en la mayor medida posible. Al sustraer la organización de la actividad económica del control de la autoridad política, el mercado elimina esta fuente de poder coercitivo y arbitrario. Se puede tener libertad económica sin libertad política, pero es dudoso que se pueda tener algún tipo de libertad política eficiente sin tener libertad económica.

El pensamiento moderno exalta la libertad, se precisa que el desarrollo tiene por finalidad obtener libertad, por ello se exige la eliminación de las principales fuentes de privación de libertad: pobreza y tiranía, la escasez de oportunidades económicas y las privaciones sociales sistemáticas. Al respecto Sen, A. (2003) precisa que las libertades fundamentales que disfrutamos para ejercer nuestras responsabilidades dependen extraordinariamente de las circunstancias personales y sociales, así como del entorno. La niña subyugada, sufre de carencias no solo desde el punto de vista del bienestar, sino también desde el punto de vista de la capacidad para llevar una vida responsable, algo que sólo puede hacerse disfrutando de ciertas libertades básicas. ${ }^{3}$ Coincidiendo con lo expuesto, Fernández, C. (2016) precisa que nos valemos de la justicia y de los demás valores para organizar la sociedad en términos de dar a cada uno lo suyo, expresión que significa que cada uno de los miembros de la comunidad cuente con las opciones u oportunidades para realizarse como seres libres, evitar aquellos grupos humanos en los cuales la lucha por subsistir les impide, ante la carencia de oportunidades realizar su proyecto de vida.

Por consiguiente, resulta necesario limitar la libertad del padre o madre de mantener relaciones incestuosas con su hijo, el padrastro o tutor con el hijastro o tutorado, del profesor con su alumno, médico con su paciente, sacerdote

\footnotetext{
3 Acota que un niño al que se le niega la oportunidad de recibir educación elemental no sólo padece una privación cuando es joven sino que, además, se lo perjudica para toda su vida.
} 
o guía espiritual con sus feligreses, todos estos menores entre 14 y 18 años, puesto que dichos actos afectan el proyecto de vida de los menores, así como porque la libre espontaneidad de los menores se encuentra limitada.

Desde el punto de vista de la psiquiatría, Querol, M. (2007), acota que la libertad es la posibilidad de vivir plenamente, sin coacciones, ni coerciones, limitantes del proceso de ser y estar vivo y de gozar de salud integral en su biotipo. El proceso de ejercer la libertad es esencial y consustancial al ser, lo es para alcanzar la satisfacción de los impulsos básicos de vida y de muerte, con todas sus manifestaciones. El amor se despliega en la libertad y esta a su vez constituye la fuente más poderosa para descubrir el amor. Por ello, resulta necesario que las prácticas sexuales que lleven a cabo los menores, se realicen libres de condicionamientos.

Por su parte el Tribunal Constitucional ha señalado:

La persona humana debe gozar del mayor grado de libertad posible en la construcción y ejecución de su propio proyecto de vida y de la satisfacción de sus propios intereses, aun cuando éstos puedan resultar irracionales para una amplia mayoría social, pues incluso el error propio (cometido a veces a expensas de altos costos personales, tanto materiales como espirituales), es fundamental para la maduración de las ideas y de las acciones futuras, cuyo libre flujo es de singular importancia en el ámbito de una sociedad democrática. Por ello, con razón se ha mencionado que en el Estado Constitucional es esencial el reconocimiento del derecho "a equivocarse". (Exp. No 0032-2010 TC/PI)

Al respecto, coincidimos que la libertad como uno de los bienes más preciados que goza el ser humano debe ser respetada y el Estado debe intervenir limitándola cuando sea absolutamente necesario, pero este reconocimiento del "derecho a equivocarse" debe otorgarse a las personas que han alcanzado la ciudadanía y en forma limitada a los menores de edad.

\section{ELECCIÓN}

Como mencionamos precedentemente, el hombre es libre de trazar su proyecto de vida $\mathrm{y}$ al hacerlo tiene que decidir lo que va a ser, pero para decidir es necesario elegir entre las posibilidades que ofrece nuestro entorno. Savater, F. (2003) precisa que la capacidad de elegir tiene como componente el Yo y la racionalidad que consiste en el proceso de evaluación de lo real, búsqueda de alternativas y toma de decisiones, acota que los motivos de estas acciones se derivan de las necesidades, deleites, compromisos, proyectos y experiencias de la persona; son estos rubros los que inciden en la elección. En este sentido es importante considerar a Fernández, C. (2016) en cuanto señala que para elegir debemos preferir, para preferir es necesario valorar, estimar, de donde la vida resulta ser un conjunto, una sucesión de valoraciones. Por eso la estructura de la vida humana es estimativa, el valorar y el estimar constituye una instancia de la vida. Los valores se insertan, de ese modo, en la realidad primaria. El decidirse es anterior a la voluntad, que es precisamente lo que pone en marcha nuestra decisión. Y el elegir, el decidirse, es una forzosidad: la forzosidad de ser libres.

De lo que se advierte que las personas y la sociedad efectúan una serie de estimaciones en las cuales, los valores juegan un rol importante; así lo relieva Medina, G. (2002):

Nuestro ordenamiento no es un sistema neutro a los valores, sino que, por el contrario, está lleno de estas consideraciones, incluso se prevé la nulidad de actos contrarios a la moral y a las buenas costumbres, también es cierto que nos encontramos en una era que se caracteriza por una mayor libertad sexual y avance en los métodos de anticoncepción. (página 91)

En el mismo sentido, Castillo, G. (2007) precisa que, para poder elegir bien, es necesario que tengamos virtudes. De esta manera, la cabeza puede estar clara para conocer la verdad y descubrir dónde está el verdadero bien y la voluntad fuerte para querer lo que vemos con nuestra inteligencia que debemos hacer. Las emociones y sentimientos impiden pensar bien, pero entonces la libertad se frustra porque ya no es la persona que en rigor elige, ya que su inteligencia y su voluntad se bloquean por el influjo de sus sentimientos descontrolados. No elige sino que se deja llevar por sus sentimientos, sus emociones, sus deseos, sus miedos, etc. El dejarse llevar comporta un ejercicio de la libertad, pero la persona no se 
manifiesta conforme a lo que tiene de más íntimo y personal, porque otras fuerzas le arrastran.

Respecto a algunas elecciones y sobre todo las que efectúan los menores de edad, en el supuesto que nos ocupa, es de relievar lo señalado por Bergman quien precisa que las elecciones se hacen dentro de un contexto determinado y fijo. Haber "hecho una elección" puede sólo significar que había alguna otra cosa que uno podía haber hecho, la cual podía haber sido aún más desastrosa que la ya nefasta alternativa que uno en realidad adoptó. La posibilidad de elegir no es garantía de libertad. Lo que somos capaces de pensar está en realidad limitado por muchos factores, nuestro pensamiento está evidentemente sometido a toda clase de influencias. Se supone que si pudo elegir era "libre" y a partir de este punto se hace derivar una pesada cadena de consecuencias Bergmann, F. (1981). En el caso que nos ocupa, las alternativas con que cuenta el menor de edad respecto a las personas de las que dependen, obviamente, son sumamente limitadas.

\section{AUTODETERMINACIÓN - AUTONOMÍA DE LA VOLUNTAD}

La autonomía de la voluntad o la facultad de decisión libre que poseen las personas para realizar sus acciones o dejar de hacerlas, es una actividad regulada por el propio sujeto, ser ley para sí mismo; en este sentido, el Tribunal Constitucional declara que la autonomía de la voluntad se refiere a la capacidad residual que permite a las personas regular sus intereses y relaciones coexistenciales de conformidad con su propia voluntad. STC 047-2004-AI/ de abril 2006. f44.

Si pensamos en un ser con razón y voluntad, tenemos que suponer la libertad, sus juicios son determinados por su razón, lo cual nos remite a la moralidad como fundamento de todas las acciones de seres racionales. El hombre tiene dos puntos de vista desde los cuales considerarse: como perteneciente al mundo sensible, sometido a leyes naturales y como miembro del mundo inteligible, independiente de la naturaleza, sometido a leyes que se fundan sólo en la razón ${ }^{4}$ Tosta, M. (1979)

\footnotetext{
4 Precisa que los deberes morales provienen de la razón del hombre, pero si son considerados como deber es porque al mismo tiempo el hombre es parte de la naturaleza y capaz de ser independiente de ella, afectado por los apetitos y las inclinaciones de la naturaleza, pero productor de leyes diferentes de las naturales.
}

Cuando el adulto aprovecha su autoridad para tener acceso carnal con el menor bajo su poder, afecta el libre y normal proceso de formación de la voluntad de estos adolescentes, se considera que entre estas edades las bases psíquicas, intelectuales e inhibitorias de los adolescentes aún no han terminado de formarse. $\mathrm{Y}$ es, precisamente, esto lo que los convierte en sujetos susceptibles a las manipulaciones de personas mayores de edad, que ejercen autoridad sobre estos.

Con relación a la autonomía de la voluntad, el Tribunal Constitucional ha señalado en la sentencia recaída en el Expediente 0017-2008PI/TC del 15 de junio de 2010, que:

Los derechos fundamentales participan de un presupuesto ético y jurídico cifrado en el principio-derecho de dignidad humana y orientado a la cobertura de una serie de necesidades básicas que permitan garantizar la autonomía moral del ser humano y el libre desarrollo de su personalidad. .... La libertad pierde su sentido axiológico si no se acompaña el conocimiento, en la libertad desinformada o desprovista de saber, anida el serio riesgo de hacer del ser humano objeto de voluntades ajenas y no sujeto de la construcción meditada de su propio proyecto de vida, así como el peligro de hacer de la persona humana un punto estático en el camino de la evolución de las sociedades, o, peor aún, un elemento promotor de la involución.

Un menor entre 14 y 18 años, no tiene experiencia de vida y precisamente, las personas que ejercen autoridad sobre él como sus progenitores, tutores, profesores, psicólogos o guías religiosos son los que le deben guiar, conducir o coadyuvar para que obtenga el conocimiento necesario para desarrollar su libertad, para que no sea objeto de voluntades ajenas.

\section{PROYECTO DE VIDA}

Vivir es realizar un proyecto de existencia, fabricar su propio ser, ser haciéndose. La vida resulta así una sucesión ininterrumpida de quehaceres según un proyecto del cual puede o no tenerse conciencia. La vida humana como proyecto es lo que se quiere hacer, contando 
con las cosas, con nuestras posibilidades y con los otros, tiene como condición la temporalidad, en el presente decidimos ser lo que queremos ser en el instante inmediato, en un futuro posible. Lo que fuimos ayer está posibilitando nuestra decisión de ser, en este poder-ser, el hombre va decidiendo lo que va a ser en el futuro. Por la libertad escojo, decido ser tal o cual cosa, más la decisión se pone en marcha por la conducta y tiene que luchar contra las resistencias. Sucumbe con ellas, pacta o las vence Fernández, C. (2015).

El derecho al libre desarrollo y al bienestar, son bienes constitucionales novedosos. Ambos derechos garantizan, aunque de distinta forma, ámbitos de libertad y realización humana. Respecto al derecho al libre desarrollo de la personalidad, este establece la libertad general de acción, es decir la posibilidad que cada quien haga lo que prefiera, sin que pueda establecerse límites inconstitucionales a ello. Sosa, J. (2015)

¿Desde qué edad las personas son conscientes de su proyecto de vida, desde que edad se debe respetar, sin restricción alguna las decisiones que adoptan las personas, sin injerencias de ningún tipo? $\mathrm{Si}$ tenemos en consideración que el proyecto de vida como señala Roca, M. (2014), "es un camino para alcanzar una meta, matizado por un cierto estilo personal y un modo de llevar adelante las acciones que conforman y brindan sentido a la existencia, al tiempo que incrementan la autoestima y la sensación de realización personal". Podemos concluir, que al culminar la adolescencia y alcanzar un mayor grado de madurez, la persona comienza a trazar su proyecto de vida.

El Tribunal Constitucional (008-2012AI) fundamento 22 , ha señalado que:

Los menores de edad entre 14 y 18 , en tanto titulares del derecho fundamental al libre desarrollo de la personalidad (en el ámbito de la libertad sexual) pueden ejercerlo...considerando... i) que conforme al principio de evolución de facultades del niño y del adolescente, debe reconocerse que tales adolescentes irán desarrollando, progresivamente, el nivel psicofísico óptimo de ejercicio del mencionado derecho fundamental, para lo cual es indispensable la educación que sobre el particular puedan brindar los padres, el Estado y la sociedad en general; $\mathrm{y}$, ii) que poseer dicha libertad sexual implica también conocer las consecuencias que puede originar su ejercicio, tal como se destaca en el mencionado "Plan Nacional de Acción por la Infancia y la Adolescencia 2012-2021", según el cual "existe consenso en que el embarazo en edad temprana es un evento que afecta la salud física, mental y social de la futura madre, así como del recién nacido.

Resulta pertinente enfatizar que este derecho se ejercerá de manera progresiva en la medida que estos desarrollan un nivel de autonomía personal. Asimismo, ha precisado en (08582003-AA/TC.2004) que en determinadas ocasiones se produce la pérdida efectiva de la autonomía privada por una de las partes, casos en los cuales los presupuestos funcionales de la autonomía privada no están suficientemente garantizados. Que en estos supuestos, en defensa de los derechos fundamentales, se permite a la persona invocar la nulidad de la relación jurídica acordada, para defenderse contra las consecuencias del propio hacer, es decir, que pueden lícitamente invocarse en la protección frente a sí mismos".

Si lo señalado precedentemente, es atendible respecto a las personas que han alcanzado la mayoría de edad, con mayor razón si se trata de menores de edad, ya que su falta de autonomía permite invocar su falta de capacidad para decidir sobre el ejercicio de actividades sexuales con las personas de las que dependen o ejercen autoridad sobre ellas, más aún, el proyecto de vida de estos se ve afectado, si resultan embarazadas por su padre, padrastro o tutor.

\section{LIBERTAD SEXUAL}

La vida, la integridad corporal, la salud, el honor, la libertad, la propiedad, el medio ambiente, entre otros, son bienes que existen $\mathrm{y}$ valen para sus titulares y para la sociedad antes que el ordenamiento jurídico los reconozca. El derecho penal toma la decisión de preservarlos en atención del significado de estos valores y la necesidad de conservarlos para asegurar el desarrollo de la persona y su convivencia pacífica; entre estos bienes jurídicos, la libertad sexual constituye un bien 
de gran relevancia, por su incidencia en la dignidad de la persona. En el mismo sentido la Organización Panamericana de la Salud, señala que los derechos sexuales y reproductivos son derechos humanos universales basados en la libertad, dignidad e igualdad inherentes a todos los seres humanos y para asegurar el desarrollo de una sexualidad saludable en los seres humanos y las sociedades, estos deben ser reconocidos, respetados y defendidos por la sociedad.

En los delitos sexuales el bien jurídico vulnerado es la libertad sexual, esto es, la facultad que tiene toda persona para autodeterminarse en el ámbito de su sexualidad, limitada por dos requisitos: el pleno conocimiento del contenido y alcance de una relación sexual y la manifestación voluntaria y libre consentimiento para participar en tal clase de relaciones -lo que se criminaliza es la libertad sexual en su sentido negativo o pasivo y supone la capacidad de rechazar las intromisiones indebidas o no deseadas en el ámbito de la propia sexualidad. San Martín, C. (2007). En este sentido se pretende que ninguna persona se vea forzada o inducida por otra a un ejercicio de sexualidad no querido o no aceptado de manera libre y consciente o aceptado con la voluntad viciada o por alguien (menores e incapaces) a cuyo asentimiento no se atribuye relevancia en la mayor parte de los casos. Orts, E. (2004)

La tutela penal se dirige esencialmente a la libertad sexual en sentido negativo, aunque debe reconocerse que la misma se relaciona también a la libertad sexual positiva, pues la capacidad de rechazar relaciones sexuales es una forma de realización de la libertad de elegir libremente a la pareja y el modo de relacionarse sexualmente. Reyna, L. (2005).

El Derecho Penal no brinda protección a la sexualidad de los menores entre 14 y 18 años, a menos que sea víctima de violencia, amenaza o engaño, o se trate de individuos que se encuentren en imposibilidad de resistir u oponerse a las prácticas sexuales. Se considera que estos menores pueden decidir sobre su sexualidad ejerciendo libremente este derecho, no se requiere que alcancen la mayoría de edad. Por ello, respecto al delito de seducción, se precisa que no se pretende garantizar el desarrollo sexual normal del adolescente, pues si ese fuera el sentido del supuesto de hecho del tipo penal, se reprimiría o prohibiría todo acto o acceso carnal sexual que se tuviera con las personas cuyas edades oscilan entre $14 \mathrm{y}$ 18 años, solo se reprime cuando media engaño o fraude, aquí se lesiona el bien jurídico autodeterminación sexual o libertad sexual. Salinas, R. (2005).

Con relación a la política criminal que ha adoptado el Estado peruano respecto a la sexualidad de estos menores, se precisa que se ha optado por dar preferencia al libre ejercicio de la sexualidad sobre cualquier otro criterio moralizante o ético, profundamente enraizado en nuestra sociedad. No brinda ningún reproche a las relaciones homosexuales, masoquistas, sádicas, incestuosas o profundamente inmorales practicadas con el libre consentimiento de las personas, luego de los 14 años. Castillo, J. (2006). Consideramos que este valor esencial para la sociedad, no se encuentra debidamente protegido.

En otras legislaciones se protege la libertad sexual de las personas que son víctimas de abuso por los individuos que ejercen autoridad o poder sobre ellas y que otorgan un consentimiento viciado para sostener actividad sexual con estos. Cancio Meliá al comentar el artículo 181.3 del Código español señala que el abuso por prevalimiento previsto en el Código Penal español hace referencia a la situación de superioridad que ha de ser manifiesta y debe suponer un vicio para el consentimiento de la víctima, el legislador ha pretendido así otorgar una protección penal amplia a la libertad sexual Cancio, M. (2005). Asimismo, es necesario tener presente la modificación introducida en el artículo 182 del Código español en cuando sanciona el abuso de una posición reconocida de confianza, autoridad o influencia sobre la víctima, realizando actos de carácter sexual con persona mayor de 16 y menor de 18 años de edad ${ }^{5}$

Asimismo, se precisa que existen otros valores indirectamente amparados en el delito de agresiones sexuales, valores tales como la dignidad personal, la intimidad, el bienestar psíquico, el riesgo de un embarazo no querido o de contagio de una enfermedad de transmisión sexual, que obviamente no constituyen el objeto formal del delito. Orts, E. (2004), siendo innegable que estas consecuencias colaterales

\footnotetext{
5 En la legislación española la indemnidad de los menores se
} extiende hasta los 16 años. 
afectan el desarrollo de la personalidad y el proyecto de vida de estos adolescentes, como veremos al analizar algunos casos de abuso sexual por prevalimiento.

\section{JURISPRUDENCIA DE LA CORTE SUPREMA DE JUSTICIA}

Casación $\mathrm{N}^{\circ} 167-20114$ de julio de 2012 - San Martín - ponente Rodríguez Tineo. Publicada en Gaceta Penal Tomo 73, julio 2015.

En el proceso penal instaurado contra Zoilo César Borrero Flores, por delito de violación de la libertad sexual, el juzgado declaró improcedente la acción penal, por considerar que la adolescente, de 14 años de edad, había prestado su consentimiento para las prácticas sexuales, por consiguiente, el hecho no constituía delito, disponiendo el archivo del proceso, al interponerse recurso de apelación, la Sala Penal, revocó la resolución de fojas 44 , y reformándola, declaró infunda la excepción de improcedencia de acción, por delito de violación sexual de menor de edad, por considerar que en la resolución de primera instancia, no se había considerado que el procesado tenía la calidad de tutor junto con su conviviente, la misma que es tía de la menor agraviada, en consecuencia, le resultaba aplicable el último párrafo del artículo $173 \mathrm{CP}$.

La resolución expedida por la Sala Superior, que revoca la de primera instancia, precisa: "una persona sujeta a la autoridad de su agresor no tiene una voluntad libre sino coactada, limitada, constreñida, por cuanto se encuentra presa de condiciones de sobrevivencia, o por lo menos de pérdida de satisfacción de sus necesidades básicas, más aún si se trata de las necesidades de una menor que ha vivido bajo la autoridad del procesado desde los 9 años".

La citada sentencia señala:

Sobre el particular es de enfatizar que al haberse dejado establecida la exención de responsabilidad penal para toda relación sexual voluntaria con adolescentes que cuentan con 14 años de edad o más, carece de trascendencia la diferencia de edades que haya entre sujeto activo y pasivo o el vínculo sentimental que exista entre ellos, en tanto en cuanto no medie violencia, grave amenaza o engaño, este último sólo relevante en el delito de seducción. Es evidente, por lo demás, que existirá delito - de acceso carnal sexual o actos contrarios al pudor- cuando se coarta, limita o anula la libre decisión de una persona en relación con su actividad sexual, para cuya determinación: ausencia de consentimiento válidamente prestado por el sujeto pasivo, ha de adecuarse al conjunto de circunstancias del caso concreto.

Asimismo, precisa la Sala Penal de la Corte Suprema que el Acuerdo Plenario N4-2008 ${ }^{6}$ resulta aplicable a toda relación voluntaria con adolescentes que tienen 14 a 18 años de edad:

Que el fundamento de dicha exención de responsabilidad penal está en la libertad sexual como la capacidad legalmente reconocida que tiene una persona para autodeterminarse en el ámbito de su sexualidad, en este sentido, cada individuo tiene el derecho de actuar de acuerdo a su propia voluntad en tanto que tales acciones no perjudiquen o dañen a otros.... en consecuencia, afirmar que el solo control de dominio sobre la víctima, esto es, se trate de alguna posición cargo vínculo familiar que le dé particular autoridad sobre la víctima o le impulse a depositar en él su confianza, es un presupuesto para fundar o excluir el ejercicio de la libertad, especialmente de la libertad sexual de la víctima, tal premisa responde a una concepción subjetiva y moralista que no condice con una concepción moderna de la libertad como autodeterminación personal y del delito como arrogación de esa capacidad de disponibilidad personal.

Respecto a lo resuelto por la Corte Suprema, es menester considerar lo siguiente: Si bien es cierto, lo resuelto por la Corte Suprema se encuentra de acuerdo a lo establecido nuestro ordenamiento legal, puesto que no se prevé el abuso sexual por prevalimiento, esto es utilizar la situación de poder, autoridad, dominio sobre el menor de edad, para acceder a prácticas sexuales con éstos, siendo una conducta atípica; también es cierto, que no consideramos correcto lo expuesto respecto a la libertad y autodeterminación de estos menores.

\footnotetext{
6 Este Acuerdo Plenario, al igual que el Acuerdo Plenario 7-2007/CJ-116, fueron emitidos en atención a la modificación del artículo 173 inciso $3 \mathrm{del}$ Código Penal por modificación del artículo 173 inciso 3 del Código Penal por
la ley $\mathrm{N}^{\circ} 28704$ de abril de 2006 , norma que sancionaba penalmente todo acceso carnal con menores de 18 años.
} 
En la presente casación la Corte Suprema cita a Stuart, "cada individuo tiene el derecho de actuar de acuerdo a su propia voluntad en tanto que tales acciones no perjudiquen o dañen a otros" en efecto el citado autor precisa, que:

La única finalidad por la cual el poder puede, con pleno derecho, ser ejercido sobre un miembro de una comunidad civilizada contra su voluntad, es evitar que se perjudique a los demás. Su propio bien, físico o moral, no es justificación suficiente, nadie puede ser obligado justificadamente a realizar o no realizar determinados actos, porque fuera mejor para él o lo haría feliz. Stuart (2011)

Pero este autor también señala: "Los que están en una situación que exige sean cuidados por otros, deber ser protegidos contra sus propios actos, tanto como contra los daños exteriores" de lo que se advierte, que el menor que se encuentra en una situación de dependencia con su tutor, quien se supone debe brindarle asistencia y cuidado, debe ser protegida cuando esta persona no cumple su rol o sus obligaciones, advirtiéndose que este consentimiento, se encuentra condicionado por una serie de circunstancias derivadas de la autoridad que éste representa. Si bien es cierto, en este proceso penal, la adolescente contaba con 14 años de edad cuando accedió a las prácticas sexuales, con su tío, una persona de 49 años con quien vivía desde los 9 años de edad; también lo es que, la circunstancia que ella haya aceptado este acceso carnal, efectuando una elección, no significa que gozara de libertad, dada su situación, siendo de aplicación lo citado precedentemente: "Sólo puede significar que había alguna otra cosa que podía haber hecho, la cual podía haber sido aún más desastrosa que la ya nefasta alternativa que adoptó"

Asimismo, en esta casación se hace referencia a lo expuesto por Miguel Polaino-Orts, en su obra Derecho Penal como sistema de autodeterminación personal, pero no se menciona que este autor, señala que el individuo ha de manifestar un respeto hacia los semejantes como personas en Derecho. El cumplimiento de la norma por parte del sujeto no es algo que afecte únicamente a él, sino algo que afecta a todo el mundo: precisamente porque la norma posibilita el contacto interactivo entre los ciudadanos, por ello el sujeto debe gestionar su ámbito de organización conforme a lo que se esperaba de él como ciudadano cumplidor de su rol, fiel al Derecho y respetuoso de los demás. Polaino - Orts, M. (2010).

Precisamente el padre, tutor, profesor, religioso tienen una serie de normas y obligaciones que observar con relación a sus dependientes o subordinados, los cuales no cumplió el citado procesado, quien incluso gravó sus encuentros sexuales con la menor, cuya difusión por internet, permitió se conocieran estos lamentables hechos, conforme se precisa en el Diario Voces de Juanjui, 23 de noviembre de 2010 .

La Sala Penal de Corte Suprema señala que pretender criminalizar esta conducta corresponde a una concepción subjetiva $\mathrm{y}$ moralista, al respecto resulta pertinente precisar, que no estamos de acuerdo con esta afirmación, puesto que, no es una concepción moralista la que nos lleva a considerar que los menores entre 14 y 18 años deben ser protegidos de los abusos señalados, sino el respeto a su libertad y autodeterminación, la misma que se encuentra restringida por su situación de dependencia. Recordemos que toda persona tiene libertad en sus gustos y en la determinación de sus propios fines, libertad para trazar su plan de vida, para obrar como quiere, sujeta a las consecuencias de sus actos, sin que se lo impidan sus semejantes, en este caso, los adultos que dan rienda suelta a sus instintos con sus dependientes, menores de edad, hacen mal uso de su libertad, afectando la autodeterminación de estos.

Si bien es cierto, el derecho penal no tiene la misión de imponer o de reforzar la moral, sino sólo la de impedir la comisión de acciones dañosas para terceros, se advierte una relación entre ambos. Hurtado señala que el núcleo original de los actos que constituyen el catálogo de acciones reprimidas penalmente está conformado por comportamientos que violan de manera grave la moral. Si bien, se reconoce la primacía del criterio de violación de bienes jurídicos, ello no significa que el derecho penal sea moralmente neutro, ya que un derecho penal que no correspondiera, en general, con la moral de su época, estaría condenado al fracaso. Hurtado, J. (2011)

Al respecto Medina, G. (1993c) refiere que la ley humana tiene por finalidad establecer la 
justicia y la paz en la comunidad, para la cual fue concebida. Solamente cuando se demuestra que una determinada conducta compromete aquellos valores, tiene la autoridad pública título para intervenir. En tanto ello no ocurra, la corrección moral de la vida de las personas queda reservada a ellas mismas, a sus familias. Lo que resulta coincidente con Casación Italiana 210974 de 5 de junio de 1998 , en cuanto señala "El carácter ilícito de los comportamientos debe ser valorado a la luz del respeto de la persona humana y de sus potencialidades para perjudicar la libertad de determinación en la esfera sexual", Jurisprudencia citada por San Martín, C. (2007).

El artículo $42^{\circ}$ del Código Civil establece que tienen plena capacidad de ejercicio de sus derechos civiles las personas que han cumplido 18 años, se supone que a esa edad la persona está dotada de suficiente madurez intelectual, equilibrio psicológico, poder de reflexión y sentido de responsabilidad para ejercer, por si misma y sin necesidad de asistencia los derechos de que es capaz desde su nacimiento. Fernández, C. (1990). Por consiguiente, si un menor de edad, decide tener relaciones heterosexuales $u$ homosexuales con su progenitor, tutor y otra persona que ejerce autoridad sobre él, no corresponde una intervención "moralista" de parte del Estado, puesto que dicho menor se encuentra en una situación de dependencia y subordinación.

\section{PROTECCIÓN JURÍDICA AL MENOR VÍCTIMA DE ABUSO SEXUAL POR PREVALIMIENTO}

La dignidad humana como principio constitucional, conlleva obligaciones que de manera general y objetiva se dirigen a la comunidad política, Estado, sociedad y particulares, mandato de respetar y proteger la dignidad humana, esto es, la persona debe ser tratada con un mínimo de consideración o respeto que merece y como mandato de no instrumentalización. Gutiérrez, W. (2015). Por consiguiente, la libertad sexual de estos menores debe ser objeto de protección por parte del Estado, como señala Sen, A. (2003, página 338):

Como seres humanos competentes, no podemos eludir la tarea de juzgar cómo son las cosas y qué es necesario hacer. Como criaturas reflexivas tenemos capacidad para contemplar la vida de otros. Nuestro sentido de la responsabilidad puede referirse a las miserias que observamos a nuestro alrededor y que está a nuestro alcance remediar, lo que es fundamental para nuestra existencia social.

Resulta pertinente tener presente lo expuesto por Diez Ripolles, J. (2003) quien acota que en toda discusión relativa al contenido y límites que debe poseer el Derecho Penal Sexual están subyacentes una serie de posturas ideológicas. Tal trasfondo ideológico, en mayor o menor medida, se encuentra detrás de toda decisión político criminal, ya que se ocupa de establecer un Derecho Penal que se adecúe lo mejor posible a su misión de proteger a la sociedad. ${ }^{7}$

Si bien es cierto, el ejercicio de la sexualidad en las personas, forma parte del libre desarrollo de su personalidad y de su dignidad, el mismo que no puede ni debe ser suprimido sin que se vulnere su capacidad de autodeterminación y el núcleo de la misma dignidad humana; también es cierto, que esta autonomía de la voluntad debe estar exenta de manipulaciones, debe ser una manifestación espontánea de su libertad sexual, por ello se señala que existe una diferencia entre vigilar las elecciones de una persona y crear más oportunidades para que los individuos puedan elegir y tomar decisiones, actuando entonces de forma responsable.

\section{CASOS EN QUE SE HA VULNERADO LA LIBERTAD}

Los menores de edad que consienten actividades sexuales con las personas que ejercen autoridad sobre ellos, lo hacen debido al temor reverencial, sumisión, respeto o miedo que sienten para con el abusador o porque son manipulados por estos.

Estos menores denuncian estos hechos, luego de mucho tiempo de haber acontecido, señalando que procesar estas vivencias ha

\footnotetext{
7 Relieva que la autorrealización personal es uno de los valores supremos de la sociedad pluralista, la concepción del ciudadano como una persona que se ocupa de desarrollar todas sus potencialidades en función de un determinado sistema de valores por él escogido presupone aceptar la idea tomar decisiones por si mismo asumiendo la dirección de su comportamiento sexual, sin ningún tipo de tutelas; el adulto tiene derecho a que se le dejen fijar sus objetivos de desarrollo personal en este ámbito.
} 
conllevado años de sentimiento de culpa, vergüenza, miedo, impotencia, frustración y cólera. Citaré 4 casos que ejemplarizan este abuso por prevalimiento:

1. Juan Borea Odría, ha sido denunciado por haber efectuado actos contra el pudor en agravio de los alumnos del colegio Héctor de Cárdenas, aprovechándose que era director del mismo, estos hechos fueron de conocimiento público después de haber transcurrido muchos años de su comisión; de los testimonios recogidos se evidencia el daño psicológico ocasionado a dichos menores víctimas de estos actos contra el pudor. (Perú 213 de marzo de 2017. Juan Borea El Director del colegio que admitió hacer cosquillas a sus alumnos.

"Durante 21 años he tenido una ira silenciosa, una pena, un dolor sonso, vergüenza e impotencia, con los años, contrariamente a lo que sucede con otro tipo de situaciones, estos sentimientos se intensificaban y se volvían más recurrentes" Daniel Mercado.

"Es luego que te das cuenta que eso era un abuso, un abuso bien feo de alguien que aprovecha su condición de poder sobre sus estudiantes". Javier Olivera.

"Pude decirle en su cara que el abusó de mi cuando niño y que es un enfermo, él lo reconoció y me dijo que estaba arrepentido y que nunca más lo había vuelto a hacer... Fue un momento muy importante en mi vida poder dejar que ese costal de piedras lo cargue este sujeto, ya que, no es culpa de nosotros lo sucedido y como comentan, no es fácil decir esto, pero el día que lo logras verbalizar es liberador". Rodrigo Gutiérrez.

"Juan Borea me usó para su placer, cuando solo yo era un niño, tenía menos de 10 años. Qué lo llevaría a pensar que yo no diría nada en esa época, quizás que a mi padre, que fue militante del MRTA lo asesinaron, quizás que era muy pobre también, y claro que necesitaba mucho estudiar, salir adelante, pero nada justifica eso, NADA. No sé por qué digo esto, en este justo momento, pero dos cosas si me motivan: primero, definitivamente todo el dolor que siento, lo segundo, que a ningún niño le debe pasar JAMAS. Ojalá esto ayude a eso" Rafael Camilo Salgado.

2. Las denuncias formuladas contra Luis Figari, fundador del Sodalicio de Vida Cristiana, German Doig y otros hermanos, por abusos sexuales que habrían llevado a cabo en agravio de jóvenes miembros de dicha comunidad cristiana.

El informe de abusos en el Sodalicio recoge, entrevistas a más de 245 personas, en él se leen testimonios de las presuntas víctimas de abuso sexual, físico y psicológico que acusan como sus agresores a Luis Fernando Figari y otros miembros de la citada congregación. Diario El Comercio 10 de enero de 2018.

El primer testimonio que aparece es de un sodálite que contó haber sido ultrajado por Figari cuando tenía 15 años de edad. "No tenía a quién acudir cuando me di cuenta de que Figari estaba abusando sexualmente de mí... Yo era joven y él era demasiado importante y poderoso como para acusarlo... He vivido con esta experiencia por más de treinta años. No desaparece."

"Después de estar con él (Germán Doig) yo llegaba a casa a llorar... No entendía lo que me estaba ocurriendo, sentía confusión, incomodidad, suciedad y culpa, pero a la vez era mi dependencia de él la que me hacía sentirme sin posibilidad de hacer algo al respecto. Él trataba de impresionarme y eso me gustaba. Necesitaba en ese momento admirar a alguien. Lo veía un poco más por arriba, a mi padre nunca lo vi así....... no puede librarse de la marca que le dejó en su personalidad: la desconfianza y la inseguridad."

3. La denuncia en un medio de comunicación contra el profesor de música Cristian Escate Chávez de 36 años de edad, docente que aprovechó esta circunstancia para convencer a su alumna del quinto año de secundaria de 16 años de edad, a fin de practicar relaciones sexuales, menor que resultara embarazada, teniendo un hijo con el citado profesor. Dos años después, este mismo profesor también mantuvo relaciones sexuales con otra alumna del colegio, quien contaba con 16 años de edad, la misma que también resultó embarazada del citado profesor. En el programa periodístico, se precisó que antes de ellas, el citado docente, también había mantenido relaciones con otra alumna del colegio. ATV del 3 de diciembre de 2017.

Del relato se advierte un reiterado abuso y aprovechamiento de esta persona en perjuicio de sus alumnas. La denunciante señala "que veía al citado profesor como un padre, le contaba los problemas que tenía en casa con su madrastra, el mismo que aprovechó estas circunstancias para 
manipularla y tener relaciones sexuales en el salón de banda del colegio Rosa de Santa María de Breña."

4. Antonio Agustín Martin, tuvo relaciones sexuales con su hijastra cuando esta contaba con la edad de 15 años, quien refiere haber comunicado estos hechos a su madre, pero ella no hizo nada al respecto, debido a que su progenitora tiene otra hija con este sujeto y es él quien mantiene el hogar. Habiendo continuado viviendo todos en la misma casa, circunstancias en las cuales ésta menor volvió a quedar embarazada, teniendo otro hijo con su padrastro. Posteriormente, se trasladó a otra vivienda, recibiendo apoyo psicológico; y, meses después decidió formular denuncia contra su padrastro. ATV del 3 de enero de 2018

De las declaraciones precedentemente glosadas, se advierte que estas víctimas, cuando eran menores de edad, fueron manipuladas e instrumentalizadas por las personas que ejercían autoridad o dominio sobre ellas, habiendo sido utilizadas para obtener una satisfacción insana, por parte del director del colegio, sacerdote, profesor y padrastro, respectivamente, quienes vulneraron la libertad $\mathrm{y}$ autodeterminación de estos menores. Estas vivencias les dejaron huellas psicológicas que permanecieron a través de los años, siendo aún mayor el perjuicio en aquellos casos en que las menores quedaron embarazadas, con lo cual se evidencia que su proyecto de vida fue seriamente afectado.

\section{CONCLUSIONES}

En aquellos casos en los cuales los menores no se oponen expresamente a estos accesos carnales, no quiere decir que prestan su libre consentimiento, ya que éste se encuentra viciado por la relación de dependencia con la autoridad que estos representan, por consiguiente, estos actos no son fruto de la autodeterminación o autonomía de la voluntad de estos menores.

Resulta de suma importancia se brinde protección a los menores que se encuentran en estado de indefensión frente a aquellas personas, que abusando de la autoridad, control o dominio que ejercen sobre estos menores, los someten a prácticas sexuales.

Estos eventos a temprana edad causan un perjuicio en el desarrollo de la personalidad de estas víctimas, en su bienestar y en varios casos, en su futuro proyecto de vida.

\section{FUENTES DE INFORMACIÓN}

\section{Fuentes bibliográficas}

Bergmann, Frithjof, (1981). El significado de la libertad. Buenos Aires, Argentina: Paidos,

Cancio Meliá, Manuel (2005). Las infracciones de violación de la libertad sexual, proxenetismo en Delitos contra la libertad e indemnidad sexual. Lima, Perú: Jurista Editores.

Castillo Alva, José Luis (2006). La muerte de la sexualidad en los adolescentes. $\mathrm{N}^{\circ} 149$. Lima, Perú: Actualidad Jurídica.

Diez Ripolles, José Luis (1981). El Derecho Penal ante el sexo. Barcelona, España: Bosch, Casa Editorial S.A.

Fernández Sessarego, Carlos (2015). en La Constitución comentada. Tomo I. Lima, Perú: Gaceta Jurídica.

Fernández Sessarego, Carlos (1990). Derecho de las personas. Lima, Perú: Cultural Cuzco

Gutiérrez Camacho Walter (2015). Dignidad de la persona, en La Constitución Comentada. Tomo I. Lima, Perú: Gaceta Jurídica

Medina, Graciela (2002). Bioética, libertad sexual y Derecho, Revista de Derecho de Familia N²1. Buenos Aires, Argentina: Bioética y Derecho de Familia.

Orts Berenguer Enrique (2004). Delitos contra la libertad e indemnidad sexuales en Derecho Penal. Parte Especial. Valencia, España: Tirant Lo Blanch Valencia.

Polaino-Orts Miguel (2010). Derecho Penal como Sistema de Autodeterminación personal. Lima, Perú: Ara Editores.

Reyna Alfaro Luis (2005). Los delitos contra la libertad e indemnidad sexual. Lima, Perú: Jurista Editores.

Salinas Siccha, Ramiro (2005). El delito de acceso carnal sexual por engaño: Seducción. Tomo 141. Lima, Perú: Actualidad Jurídica.

Savater, Fernando (2003). El valor de elegir. Barcelona, España: Ariel. 
Sen Amartya (2003). Desarrollo y libertad. Bogotá, Colombia: Planeta.

Sosa Sacio Juan Manuel (2015). Derecho al libre desarrollo y al bienestar, en $\mathrm{La}$ Constitución Comentada. Tomo I. Lima, Perú: Gaceta Jurídica.

Stuart Mill, Jhon (2011). Sobre la libertad. Madrid, España: Alianza Editorial.

Tosta de Martínez, María Luisa (1979). La libertad en la Teoría Pura del Derecho, en Libro Homenaje a Rafael Pizani. Caracas, Venezuela: Universidad Central de Venezuela.

\section{Fuentes electrónicas}

Andrea Llosa (2018). Qué fue de la mujer que culpó a su hija de "permitir" ser violada por padrastro. Recuperado de http://www. atv.pe/actualidad/que-fue-de-la-mujer-queculpo-a-su-hija-por-permitir-ser-violada-porpadrastro-345471

Berlin Isaiah (1958). Dos conceptos de libertad, Recuperado del sitio de internet: https:// wold.fder.edu.uy/contenido/rrll/contenido/ licenciatura/isaiah-berlin-dos-conceptos-delibertad-1858.pdf

Castillo Córdova, Genara. (2007). Libertad esencial y libertad trascendental. En L. González (Ed.), la libertad y sus realizaciones. Piura: UDEP. Recuperado del sitio de internet: https://pirhua.udep.edu.pe/bitstream/ handle/11042/1654/Libertad_esencial_y_ libertad trascendental.pdf?sequence $=1$

Castillo Córdova, Luis (2006). Autonomía de la voluntad y derechos fundamentales. Actualidad Jurídica. Lima, Perú. Recuperado del sitio de internet: https://pirhua.udep.edu.pe/bitstream/ handle/11042/1942/Autonomia_voluntad_ derechos_fundamentales.pdf? sequence $=1$

Constanza Mazzina, Francisco (2007). ¿Qué es la libertad? Revista de la Facultad de Ciencias Económicas de la Universidad Francisco Marroquín, Número 26. Recuperado del sitio de internet: http://laissezfaire.ufm.edu/index. php/Laissezfaire26_4.pdf

El Comercio (2017). Caso Soladicio: el doloroso testimonio de una víctima de abuso sexual. Recuperado de https://elcomercio.pe/ lima/judiciales/caso-sodalicio-testimoniovictima-abuso-sexual-433113
El Comercio (2018). Sodalicio: los dolorosos testimonios de las víctimas de abusos. Recuperado de https://elcomercio.pe/lima/ sodalicio-escabrosos-testimonios-victimasabusos-403477

Farrel, Martín (1989). Libertad negativa y Libertad positiva. Número 2. Revista del Centro de Estudios Constitucionales. Universidad de Buenos Aires. Recuperado del sitio de internet: https://dialnet.unirioja.es/ descarga/articulo/1048528.pdf

Organización Panamericana de la Salud (2013). Salud del adolescente. Recuperado de: https:// www.paho.org/hq/index.php?option=com top ics\&view $=$ article $\&$ id $=223 \&$ Itemid $=40879 \&$ la $\mathrm{ng}=\mathrm{es}$

Perú 21 (2017). Juan Borea Odría, el director de un colegio que admitió hacer "cosquillas" a sus alumnos. Recuperado de https://peru21. pe/lima/juan-borea-odria-director-colegioadmitio-cosquillas-alumnos-67734

Querol, Mariano (2007). La libertad de ser ila libertad o las libertades? Recuperado del sitio de internet: www.upch.edu.pe/ vrinve/dugic/revistas/index.php/RNP/article/ view/1613/1641

Quevedo Bardalez, Lenin (2010). Fue detenido acusado de presunta violación. Diario Voces. [Nota periodística]. Recuperado de https:// diariovoces.com.pe/web/?p=17762/

Roca Perara, Miguel Ángel (2014). Proyecto de vida en los jóvenes. Revista de divulgación cientifica y cultura de la salud en cuba. Recuperado de http://www.saludvida.sld.cu/ articulo/2014/01/07/proyecto-de-vida-en-losjovenes

San Martín Castro (2007). Delitos contra la libertad sexual y delitos contra la Familia. Proyecto de Mejoramiento de los servicios de Justicia del Banco Mundial- Poder Judicial, Lima. Recuperado del sitio de internet: http://historico.pj.gob.pe/CorteSuprema/ cij/documentos/DELITO_LIBER_SEX BM_101108.PDF

Zuñiga Rudy (2017). El caso del profesor que embarazó a dos alumnas menores de edad. Recuperado de http://www.atv.pe/actualidad/ el-caso-del-profesor-que-embarazo-a-dosalumnas-menores-de-edad-343665 